\title{
Developing New Strategies for the Treatment of Tuberculosis Employing Ruthnium(II)Quaterpyridyl Compexes
}

\author{
Megh Raj Pokhrel, ${ }^{1, *}$ Pubudu Gamage ${ }^{2}$, Mausam Kalita ${ }^{2}$, \\ Aibin Shi ${ }^{2}$ and Stefan H. Bossmann ${ }^{2}$ \\ 1. Central Department of Chemistry, Tribhuvan University, Kathmandu, Nepal \\ 2. Department of Chemistry, Kansas State University, Manhattan, KS 66506-3701, USA
}

\begin{abstract}
A series of ruthenium(II)quaterpyridyl complexes has been synthesized as prototypes for mycobacterial channel blockers. These Ru(II)complexes show distinct changes in their luminescence spectra when bound to the porin MspA from $M$. smegmatis, which is a non-pathogenic relative of $M$. tuberculosis. By using HPLC, we have determined binding constants of the Ru(II)-complexes to MspA in phosphate buffer $(0.05 \mathrm{M}, \mathrm{pH}=6.8)$ ranging from $5.2 \times 10^{9} \mathrm{M}^{-1}$ (Ru-C2) to $1.8 \times 10^{9} \mathrm{M}^{-1}$ (RuC4). Our findings indicate that channel blocking is a promising treatment strategy for mycobacterial infections. It appears to be also a viable approach towards luminescent nanostructures, because MspA features extraordinary stability.
\end{abstract}

Keywords: Ru(II)complexe, porin MspA, mycobacterial infection, tuberculosis.

\section{Introduction}

Mycobacterium tuberculosis is, according to the World Health Organization, one of the most dangerous infectious diseases; causing more deaths than any other single infection. ${ }^{1}$ Approximately one third of the world's population is already infected. More than 4,000,000 new cases and more than 2,000,000 deaths have to be accounted for each year. ${ }^{1}$ Multi-resistant strains have appeared due to the discontinuing treatment of tuberculosis in many countries, threatening all countries which experience immigration during the last two decades. Therefore, entirely new strategies are required to obtain the basic knowledge, which will then enable the successful development of new anti-TB-therapies. Mycobacteria possess an especially thick outer membrane (called "cell envelope"), which acts as a hydrophobic shield against antibiotics. ${ }^{2}$ Channel proteins ("porins") form the main

\footnotetext{
* Corresponding author
} 
hydrophilic pathways through the cell envelope. The porin from $M$. smegmatis (MspA) was employed as model channel from a bacterium, which is closely related to $M$. tuberculosis, but non-pathogenic. The MspA can serve as an ideal host system for highly-charged ruthenium(II)-quaterpyridyl complexes, because it possesses 16 aspartates in its constriction-zone of the diameter of approximately $1 \mathrm{~nm}$. It has recently been reported that the luminescence and HPLC-studies comprising MspA ${ }^{3}$ and a series of four synthesized ruthenium(II)polypyridyl complexes. ${ }^{4}$ The geometric dimensions of the $\mathrm{Ru}$ (II)-complexes have been optimized to permit optimal binding within the inner pore of MspA. The biggest driving force for the observed binding is the charge attraction between the negatively charged inner pore of the MspA and the positively charged Ru(II)-complexes.

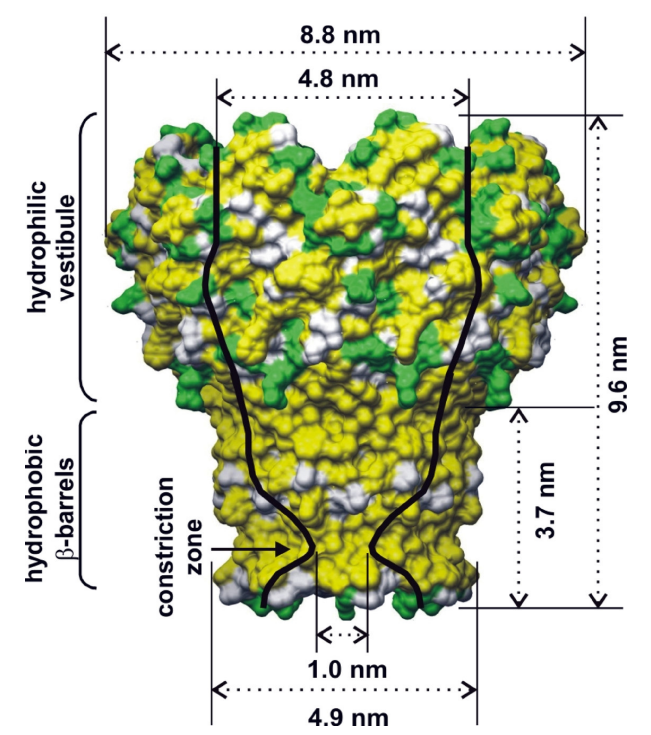

Figure 1: The structure of MspA (PDB-code 1UUN): yellow: hydrophobic amino acids; green: hydrophilic amino acids. ${ }^{3}$

Proteins are macromolecules with dimensions in the nanometer range and can be tailored to specific needs by site-directed mutagenesis. However, their use in nanotechnology has been severely hampered by the problem that most proteins lose their structural integrity in a non-native environment, impeding their use in technical processes. ${ }^{5}$ The MspA porin from M. smegmatis is an extremely stable protein, retaining its channel structure even after boiling in $3 \% \mathrm{SDS}$, heating to $100^{\circ} \mathrm{C}$ or extraction with organic solvents. ${ }^{6}$ A distinct advantage of MspA is its amphiphilic nature. Not only is the interior channel surface much more hydrophilic than its exterior, the exterior is subdivided in two distinct zones. The MspA features a very hydrophobic "docking region" at the stem of its "goblet", whereas its "rim" section is formed by alternating hydrophilic and hydrophobic residues so that it is much 
more hydrophilic. The geometric dimensions of the "docking region" are $3.7 \mathrm{~nm}$ in length, and $4.9 \mathrm{~nm}$ in diameter as shown in Fig. 1.

\section{Experimental Methods}

The MspA was grown in laboratories using established procedures as described elsewhere. ${ }^{7}$ The synthesis of ruthenium(II)-tris-(4,4',2',2', 4', ,4, , quaterpyridinium) (Fig. 2) complexes is described in the literature. ${ }^{4}$ Shortly, dimerization of 4,4'-dipyridyl on $\mathrm{Pd}$ /carbon in anhydrous $\mathrm{DMF}$ leads to quaterpyridyl in $20 \pm 2 \%$ yield. $\mathrm{Ru}(\mathrm{DMSO})_{4}{ }^{2+}$ reacts with quaterpyridyl in $\mathrm{MeOH}$ at $1000 \mathrm{psi}$ and $100^{\circ} \mathrm{C}$ quantitatively to $\mathrm{Ru}(\mathrm{II})$-tris-quaterpyridyl $\left(\mathrm{Ru}(\mathrm{II})(\mathrm{QP})_{3} \mathrm{Cl}_{2}\right.$ ). Quaternization of the exterior $\mathrm{sp}^{2}$-nitrogen functions was achieved by reacting them with the organic bromides (R-Br) in $\mathrm{MeOH}$ at $1000 \mathrm{psi}$ and $40^{\circ} \mathrm{C}$. Purification of the tris-homoleptic ruthenium(II) complexes and exchange of the counter-anions against chloride is performed by anion exchange chromatography on Sephadex.

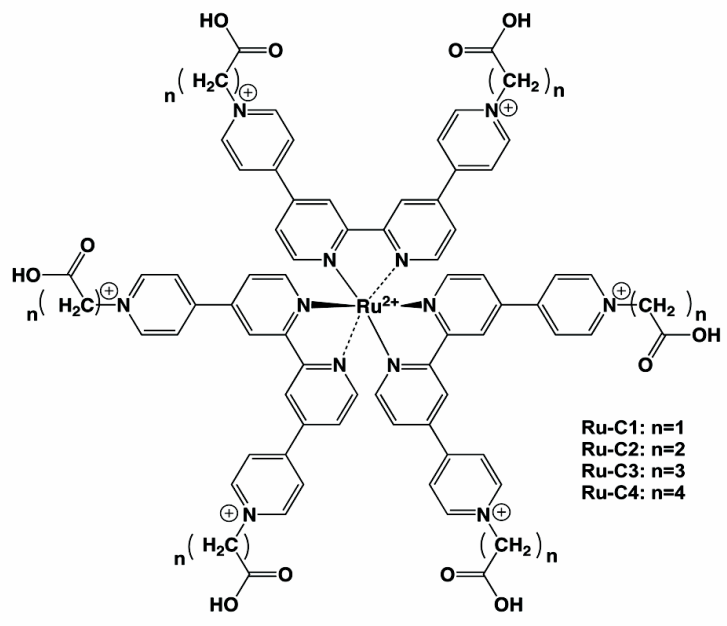

Figure 2: Ruthenium(II)-tris-(4,4',2',2', 4,',4,' ' quaterpyridinium) complexes $\mathrm{Ru}(\mathrm{II})-\mathrm{Cl}$ to $\mathrm{Ru}(\mathrm{II})-\mathrm{C} 4^{4}$

\section{UV/Vis-Absorbance and Luminescence Experiments}

Both experiments were carried out in $4.0 \mathrm{~mL}$ quartz-cuvettes (Helma) using a spectrofluoro-meter (Fluoromax2) with dual monochromators and a diode array UV-vis absorption spectrometer (HP 8453). 0.05M Phosphate buffer ( $\mathrm{pH}=6.8$ ) was used as solvent. 
HPLC-determination of the binding constants of the Ru(II)quaterpyridyl complexes to $M s p A$

The binding constants of both of small and large gold nanoparticles bound to MspA were measured by HPLC (Shimadzu Prominence) employing a POROS $\mathrm{HQ} / 20$ anion exchange column and a flux of $0.50 \mathrm{ml} \mathrm{min}^{-1}$. Two buffers were used: AOP05 (25mM HEPES, pH 7.5, $10 \mathrm{mM} \mathrm{NaCl}, 0.5 \%$ OPOE) and BOP05 (25 mM HEPES, pH 7.5, $2 \mathrm{M} \mathrm{NaCl}, 0.5 \%$ OPOE). A typical gradient was 100\% AOP05 (0-5 min.), followed by a linear gradient to $100 \%$ BOP05 (5-35 min.). The eluent was kept at 100\% BOP05 (35-50 min.). Finally, the salt concentration is returned linearly to $10 \mathrm{mM}(100 \%$ AOP05) (50-60min). The stop time was set at $65 \mathrm{~min}$. Peak detection was achieved using UV/Vis-absorbance(diode-array). The binding constants were calculated according to equation (1):

$$
K_{B}=\frac{[R u(I I) c p x @ M s p A]}{\left([R u(I I) c p x]^{0}-[R u(I I) c p x @ M s p A]\right)\left([M s p A]^{0}-[R u(I I) c p x @ M s p A]\right)}
$$

where, $\mathrm{K}_{\mathrm{B}}$ :binding constant, $[\mathrm{Ru}(\mathrm{II}) \mathrm{cpx} @ \mathrm{MspA}]$ :concentration $(\mathrm{mol} / \mathrm{L})$ of the supramolecular assembly of the ruthenium(II)quaterpyridyl complexes $\mathrm{Ru}-\mathrm{C} 1$ to Ru-C4 and MspA; [MspA] $]^{0}$ :concentration of MspA (mol/L) in the absence of NP's; $[\mathrm{Ru}(\mathrm{II}) \mathrm{cpx}]^{0}$ :starting concentration of the ruthenium(II)quaterpyridyl complexes $(\mathrm{mol} / \mathrm{L})$.

\section{Results and Dicussion}

\section{Ruthenium(II)polypyridyl complexes}

Ruthenium(II)-polypyridyl complexes possess extraordinary thermal and photochemical stabilities. They are also kinetically stable, which means that they usually do not show ligand-exchange reactions in the dark. ${ }^{8}$ Since they possess $\mathrm{D}^{3}$ geometries when three equal ligands are employed (tris-homoleptic complexes), their geometric extensions can be estimated employing molecular modeling methods. ${ }^{9}$ Furthermore, it should be noted that ruthenium(II)-polypyridyl complexes absorb light in the UV- and Vis-region up to $\lambda=550-650 \mathrm{~nm}$, depending on their ligand structures. Finally, it should be noted that the redox potentials of $\mathrm{Ru}(\mathrm{III})$-, $\mathrm{Ru}(\mathrm{II})-$ and $\mathrm{Ru}(\mathrm{I})$-complexes are easily accessible. ${ }^{10}$

\section{Ruthenium(II)-quaterpyridinium complexes and their binding within MspA}

Due to their positive charges and geometric dimensions (Table 1), Ru(II)quaterpyridyl complexes are the ideal guests for the MspA-pore. However, it must 
be noted that these complexes can undergo partial deprotonation at neutral $\mathrm{pH}$. This process is able to diminish their net positive charges (maximally eight) to a certain extent. Quantitative data on the acid/base-properties of Ru-C1 to RuC4 are not yet available. The presence of the aspartate residues D90 and D91 provides up to 16 negative counter anions for the Ru (II)-complexes. Our results indicate a strong charge attraction and consequent binding of the Ru (II)-complex within the pore of MspA have been obtained (see below).

\section{UV/Vis-absorption characteristics}

The first step of the photophysical characterization of the ruthenium (II) complexes consisted in the determination and the assignment of the major absorption peaks. ${ }^{10}$ Our results are summarized in Table 1.

Table 1. Absorption Coefficients of Ru(II)quaterpyridyl complexes in phosphate buffer at pH $=6.8$.

\begin{tabular}{cccc}
\hline Complexes & $\lambda_{\max } \mathrm{nm}$ & $\varepsilon\left(\mathrm{M}^{-1} \mathrm{~cm}^{-1}\right)$ & Assignment \\
\hline \multirow{2}{*}{$\mathrm{Ru}(\mathrm{II})-\mathrm{C} 1$} & 257 & 70452 & $\pi \rightarrow \pi^{*}$ \\
& 323 & 26202 & $\mathrm{~d} \rightarrow \pi^{*}$ \\
& 491 & 17352 & ${ }^{3} \mathrm{MLCT}$ \\
$\mathrm{Ru}(\mathrm{II})-\mathrm{C} 2$ & 258 & 111358 & $\pi \rightarrow \pi^{*}$ \\
& 316 & 30610 & $\mathrm{~d} \rightarrow \pi^{*}$ \\
& 490 & 18708 & ${ }^{3} \mathrm{MLCT}$ \\
$\mathrm{Ru}(\mathrm{II})-\mathrm{C} 3$ & 248 & 71808 & $\pi \rightarrow \pi^{*}$ \\
& 309 & 39478 & $\mathrm{~d} \rightarrow \pi^{*}$ \\
& 479 & 16454 & ${ }^{3} \mathrm{MLCT}$ \\
$\mathrm{Ru}(\mathrm{II})-\mathrm{C} 4$ & 257 & 107416 & $\pi \rightarrow \pi^{*}$ \\
& 306 & 36231 & $\mathrm{~d} \rightarrow \pi^{*}$ \\
& 481 & 15523 & ${ }^{3} \mathrm{MLCT}$ \\
\hline
\end{tabular}

As it can be discerned from the four comparisons between the $\mathrm{Ru}$ (II)quaterpyridinium complexes $\mathrm{C} 1$ (Figure 3, upper left), C2 (upper right), C3 (lower left), and C4 (lower right), only minor changes occur in the UV/Vis-spectra if MspA is present. We attribute these changes to the formation of supramolecular adducts between the ruthenium complexes and MspA. However, it is impossible to determine the strength of this interaction from the UV/Vis-spectra. Therefore, we have performed steady-state luminescence spectroscopy and HPLC-determinations of the binding constants.

In Fig. 4, four comparisons between the Ru (II) quaterpyridinium complexes $\mathrm{C} 1$ (upper left), $\mathrm{C} 2$ (upper right), C3 (lower left), and C4 (lower right) in water (pH $=6.8$ ) and in the presence of MspA are shown.

\section{Steady-state luminescence spectroscopy}


The luminescence data summarized in Fig. 4 shows the typical behavior for ruthenium(II)-polypyridyl complexes which are bound by proteins. ${ }^{11}$ The luminescence arising from the ${ }^{3} \mathrm{MLCT}$ (metal to ligand charge transfer) of the $\mathrm{Ru}(\mathrm{II})$-complexes is partially quenched by $\mathrm{H}_{2} \mathrm{O} .{ }^{12}$ When binding occurs, the complex is stripped of a part of its hydrate shell. Therefore, the quantum yield of luminescence often increases. This behavior is especially pronounced for $\mathrm{Ru}$ (II)- $\mathrm{C}_{2}$. However, proton quenching can decrease the luminescence intensity and, therefore, a significant increase cannot be observed. Apparently, this is the case for the binding of $\mathrm{Ru}$ (II)-C1.

A second mechanistic criterion is the occurrence of a red shift of the luminescence-maximum upon complex binding. In tris-homoleptic complexes, which we exclusively use in these studies as luminescence probes, this shift is caused by the extension of the "ligand-field" surrounding the metal center due to supramolecular interaction with the biological structure. ${ }^{11}$ As it becomes apparent from Figs 4 and 5, the magnitude of the red shift of luminescence increases with increasing size of the complex. ${ }^{13}$
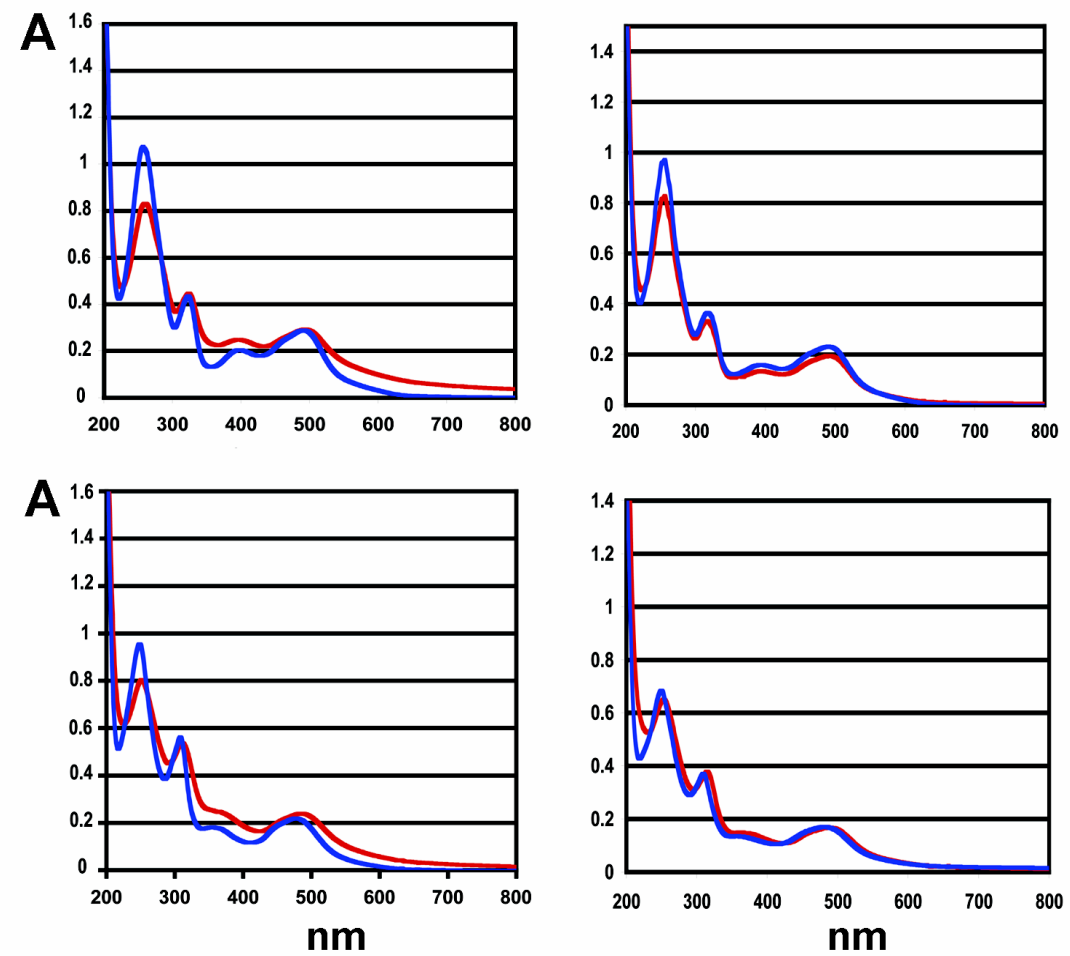

Figure 3: UV/Vis-Absorption Spectra of the Ruthenium (II)-tris-(4,4',2',2,',4',,4, ' quaterpyridinium) complexes $\mathrm{Ru}(\mathrm{II})$-C1 to $\mathrm{Ru}(\mathrm{II})$-C4 (approx. $1.15 \times 10^{-5} \mathrm{M}$ in the presence (red) and absence (blue) 
J. Nepal Chem. Soc., Vol. 23, 2008/2009

of $\operatorname{MspA}\left(10 \mu g L^{-1}\right)$.
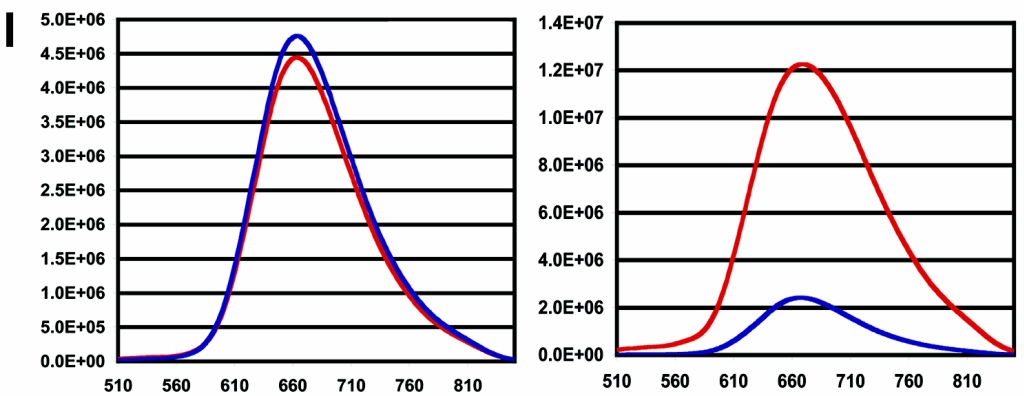

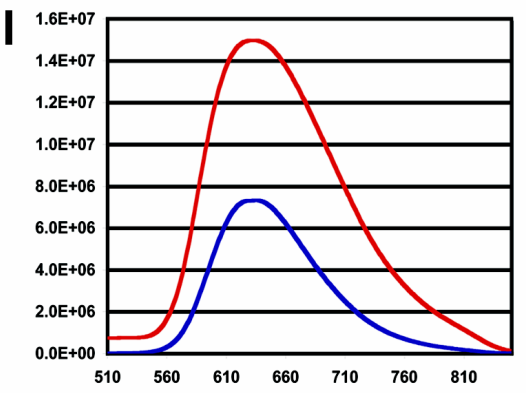

$\mathrm{nm}$

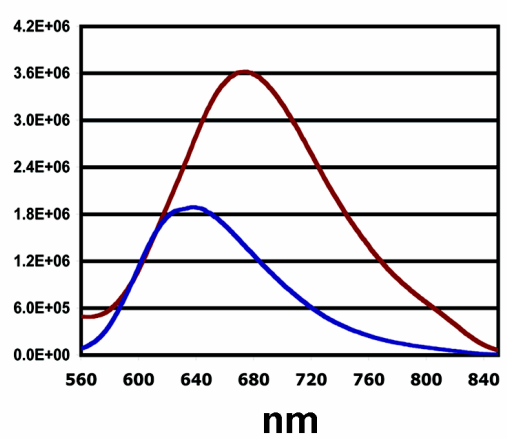

Figure 4: Luminescence Spectra of the Ruthenium(II)-tris-(4,4',2',2', 4',,4', ' quaterpyridinium) complexes $\mathrm{Ru}(\mathrm{II})$-Cl to $\mathrm{Ru}(\mathrm{II})$-C4 (approx. $1.15 \times 10^{-5} \mathrm{M}$ in the presence (red; outer spectra except

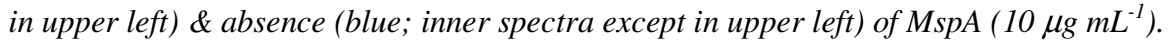

A

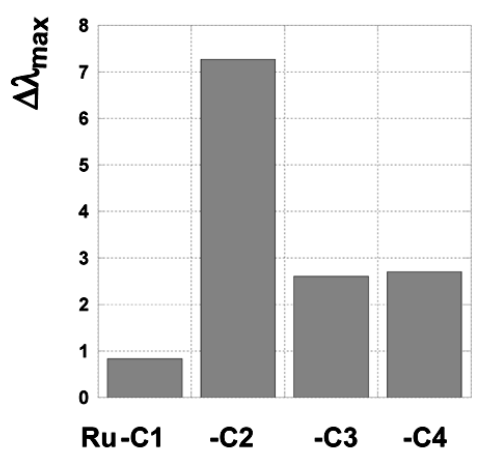

B

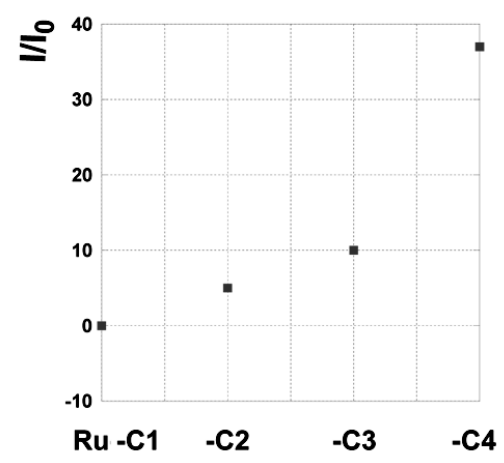

Figure 5: Indications for Binding of Ru(II)-C1 to C4 - complexes within MspA A: Luminescence enhancement is a strong indication for the binding of Ru(II)-polypyridyl complexes. ${ }^{11} \mathrm{~B}: \mathrm{A}$ consecutively progressing shift in the wave-length of the emission maximum is indicative of different binding sites of various $R u(I I)$-quaterpyridinium complexes of increasing diameters $(C 1>C 4)$ within MspA. 
J. Nepal Chem. Soc., Vol. 23, 2008/2009

Table 2: Highly charged ruthenium(II)-quaterpyridinium complexes with diameters in nano-particle range and binding constants within MspA, as determined by HPLC.

\begin{tabular}{|c|c|c|c|}
\hline $\mathrm{Ru}(\mathrm{II})-$ complex & $-\left(\mathrm{CH}_{2}\right)_{\mathrm{n}^{-}}$ & $\mathrm{d}[\mathrm{nm}]$ & $\mathrm{K}_{\mathrm{B}}\left[\mathrm{M}^{-1}\right]$ \\
\hline $\mathrm{Ru}-\mathrm{C} 1$ & 1 & 2.43 & $7.5 \times 10^{9}$ \\
\hline $\mathrm{Ru}-\mathrm{C} 2$ & 2 & 2.92 & $5.8 \times 10^{9}$ \\
\hline $\mathrm{Ru}-\mathrm{C} 3$ & 3 & 2.99 & $3.4 \times 10^{9}$ \\
\hline $\mathrm{Ru}-\mathrm{C} 4$ & 4 & 3.18 & $1.1 \times 10^{9}$ \\
\hline
\end{tabular}

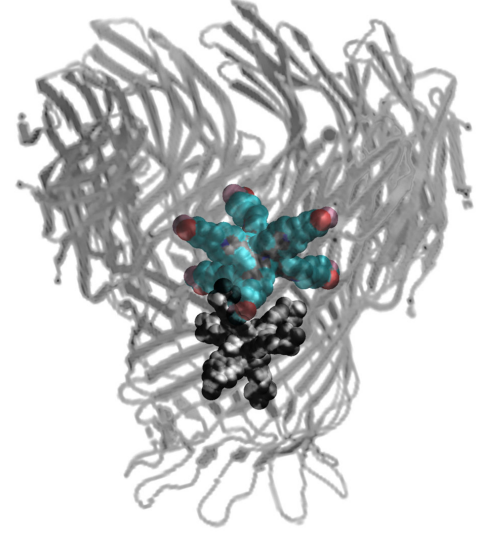

Scheme 1: Modelling of the Binding of two Ru(II)-complexes to MspA Ru(II)-C1: black; Ru(II)-C4: coloured

\section{Conclusions}

The experimental data obtained from steady-state luminescence and HPLC are indicative of binding of the ruthenium (II) quaterpyridyl complexes at/within MspA. HPLC indicated very high binding constants. This behaviour could be expected because of the presence of a double ring of aspartates in the constriction zone of MspA (D90 and D91) and the positively charged ruthenium (II)complexes. Interestingly, neither the observed luminescence enhancement nor the red shift of the luminescence correlate with the measured binding constants. $\mathrm{Ru}$ (II)-C1 binds most strongly because it is the smallest complex and can, as modelling indicates, be closest to the constriction zone (Figure 1). Therefore, it is certainly stripped of a part of its hydrate shell. As a result, its quantum yield of luminescence should increase, but a slight decrease is observed instead. This unexpected behavior can be attributed to the presence of the 16 aspartic acid units (D90 and D91) in the homo-octameric MspA. At an (outer) $\mathrm{pH}$ of 6.8 , we can expect that not all aspartic acids are deprotonated. Therefore, proton quenching may occur. $\mathrm{Ru}(\mathrm{II})-\mathrm{C} 2$ shows the strongest luminescence enhancement, whereas $\mathrm{Ru}(\mathrm{II})-\mathrm{C} 3$ and $\mathrm{Ru}(\mathrm{II})-\mathrm{C} 4$ exhibit luminescence enhancement to a lesser extent when bound to MspA. However, they 
show the largest red shifts in luminescence due to an enhanced ${ }^{3}$ MLCTdelocalization. The observed differences in luminescence enhancement and red shift clearly prove that each ruthenium(II)complex is bound at a different location inside the vestibule of MspA due to increasing diameter and the funnel-shape of the inner MspA pore. Our results indicate that channel blockers featuring high binding constants to mycobacterial porins can be designed. $\mathrm{Ru}$ (II)-complexes are especially suited for photophysical experiments, however Zn(II)-polypyridyl complexes may be better suited for in-vivo applications due to their lower toxicity.

\section{Acknowledgements}

The authors thank Dr. Dan Higgins for the use of his instrumentation and NSF-EPSCoR (First Award \#4166) for financial support of this research.

\section{References}

1. www.who.int

2. M. Niederweis and S. H. Bossmann, Encyclopedia of Nanoscience and Nanotechnology, 2004, 7, 851-867.

3. M. Faller, Niederweis, M. and Schulz, G. E., Science, 2004, 303, 1189-1192.

4. A. Shi, Pokhrel, M. R. and Bossmann, S. H., Synthesis, 2007, 4, 505-514.

5. H. Engelhardt, Gerbl-Rieger, S.; Krezmar, D.; Schneider-Voss, S.; Engel, A. and Baumeister, W., J. Struct Biol., 1990, 105, 92-102.

6. M. Niederweis, Mol. Microbiol., 2003, 49, 1167-1177.

7. C. Heinz, Roth, E. and Niederweis, M., Meth. Mol. Biol., 2003, 228, 139-150.

8. H. Duerr and S. H. Bossmann, Acc. Chem. Res., 2001, 34, 905-917.

9. D. A. Lutterman, Chouai, A.; Liu, Y.; Sun, Y.; Stewart, C. D.; Dunbar, K. R. and Turro, C., J. Am. Chem. Soc., 2008, 130, 1163-1170.

10. A. Juris, Balzani, V.; Barigelletti, F.; Campagna, S.; Belser, P. and Von Zelewsky, A., Coord. Chem. Rev., 1988, 84, 85-277.

11. A. M. Pyle, Rehmann, J. P.; Meshoyrer, R.; Kumar, C. V.; Turro, N. J. and Barton, J. K., J. Am. Chem. Soc., 1989, 111, 3051-3058.

12. C. Turro, Bossmann, S. H.; Leroi, G. E.; Barton, J. K. and Turro, N. J., Inorg. Chem., 1994, 33, 1344-1347.

13. (a) N. J. Turro, Barton, J. K. and Tomalia, D. A., Acc. Chem. Res., 1991, 24, 332-340. (b) N. J. Turro and Barton, J. K., Paradigms, Supermolecules, electron transfer and chemistry at a distance. What's the problem? The science or the paradigm?, JBIC, 1998, 3, 201-209. 
J. Nepal Chem. Soc., Vol. 23, 2008/2009 